\title{
MAPPING THE IRRIGATION AREA OF WINTER WHEAT FARMLAND IN NORTH CHINA PLAIN USING MODIS REMOTE SENSING DATA
}

\author{
Lin Lu ${ }^{\mathrm{a}}$, Qin Zhihao ${ }^{\mathrm{a}, *}$, Li Jingjing \\ anternational Institute for Earth System Sciences, Nanjing University, Hankou Road 22, Nanjing - nju0596@126.com \\ *International Institute for Earth System Sciences, Nanjing University, Hankou Road 22, Nanjing - qinzh@caas.net.cn
}

KEY WORDS: Irrigation Mapping, North China Plain, Agriculture, Water Shortage, MODIS data

\begin{abstract}
:
North China Plain is one of the most important agricultural regions in China with severe challenges of water shortage. Agriculture in the plain is very intensive. Farming in the region is a typical irrigation-supported system of winter wheat, followed by summer maize. Other important crops in the region include cotton, potatoes, soybean and various vegetables. Cultivation of these crops requires large amount of irrigation water to support harvest. However, water resource is very limited due to high evaporation and unbalanced precipitation. Though annual precipitation of the region is about $600-800 \mathrm{~mm}$, water shortage has been a common social-economic problem in the region, resulted from rapid increase of economic development and intensive farming. Both surface and underground water resources in the region have been over-extracted to meet the rapid increase of various demands on water, leading to omens of water scarcity disasters in the region. The ground water level has felled down at a rate of about $1 \mathrm{~m}$ per year in recent decades. Consequently, several big fluvial crateriforms have been observed in the region, corresponding to over-pumping ground water for years. Since agriculture consists of the largest component of water uses, mapping irrigation area for estimation of agricultural water demand is urgently required to improve the administration of water resource for effective utilization in the region. In this paper, we present our systematic investigation of mapping the irrigation area in the plain using MODIS remote sensing data. Since water demand for irrigation is generally related with the cropping systems during the season when rainfall is few, we have to examine the cropping structure of the region so that the important cropping systems requiring irrigation can be identified. Spectral behaviors of the cropping systems in MODIS data have to be investigated for construction of algorithm to identification of the systems in the MODIS images. Winter wheat has been identified as the main cropping systems requiring intensive irrigation during the growing season from March to early June. The normalized difference of vegetation index (NDVI) has been widely used to identify green vegetation in remote sensing images. Since winter wheat and forest is the main green vegetation during the March and April when other crops has not been planted, change trend of NDVI of farmland and forest can be used to identify winter wheat and forest, which can then be used as the input for irrigation mapping. Then Vegetation Supply Water Index (VSWI) has been used in this paper for identifying irrigated area in winter wheat field. VSWI is the ratio of NDVI and temperature. It combines the information of temperature and growing condition of vegetation together, which can indicate humidity of soil more exactly.According to our study in North China plain, irrigation area can be properly mapped for estimation of agricultural water demand using the MODIS data. Total irrigation area of the region is about 5.9 million hectares in 2006. This figure is smaller than that from statistical yearbook. The mapping results indicate that the spatial variation of irrigation area is very obvious in the region. More intensive irrigation can be observed on the southern Hebei Province, the northern and the eastern Henan province. Irrigation percentage in these areas can reach up to $70 \%$ for the winter wheat. In the future study, agricultural water demands for various areas will be estimated on the basis of the irrigation mapping.
\end{abstract}

\section{INTRODUCTION}

North China Plain is one of the most important agricultural regions in China with severe water shortage. Farming in the region is a typical irrigation-supported system of winter wheat, followed by summer maize. Agricultural productivity is limited by quantity of irrigation water. In the region, the annual precipitation is $600-1000 \mathrm{~mm}$ with obvious spatial heterogeneity. From July to September it is rainy season, however, growing periods of most crops especially the major winter wheat when crops need abundant water is from March to May. Ground water become the dominate irrigation water in the region due to shortage and spatial heterogeneity of surface water. However, there are large funnel-shaped hollows because of long term over-extract ground water. The present situation stated above necessitates effective measures to solve the conflict between the development of agriculture and the lack of irrigation water. Therefore, mapping the irrigation area for estimation of agricultural water demand in North China Plain is significant.
Early researchers have demonstrated the ability of remote sensing imagery to map irrigated land and update irrigation area. In primary work, manual interpretation of irrigated land based on Landsat TM imagery and comparison interpreted results with in situ data have been carried out (Draeger, 1976; Heller and Johnson, 1979; Rundquist et al., 1989). Subsequently, aerial photograph was used for assistant interpretation with Landsat TM imagery. However, it is laborious, costly and time-consuming for manual interpretation. And it is also highly influenced by personal manipulation and experience.

From the late 1980s, vegetation index derived from remote sensing data to determine actual irrigated land has been proposed. Vegetation index has been demonstrated to be an effective index to quantify the concentrations of green leaf vegetation and to identify where plants are thriving and where they are under stress (i.e., due to lack of water) (John Weier and David Herring). Subsequently, studies of agricultural land using multi-spectral imagery have shown that Normalized Difference of Vegetation Index (NDVI) is a sufficiently good indicator of irrigation 
presence, irrigation status and crop condition (Pax-Lenney et al., 1996; Abuzar et al., 2001; Martinez-Beltran and Calera-Belmonte, 2001). In these studies, it has been shown that single date imagery acquired at the peak of the growing season may be sufficient to identify irrigation area, while multi-date data is needed to distinguish different irrigated crop types (Rundquist et al., 1989; Abuzar et al., 2001).

In the last decade, a number of methods have been developed to determine the timing of vegetation sprouting and senescence using time series of NDVI derived from the Advanced Very High Resolution Radiometer (AVHRR) and Moderate Resolution Imaging Spectroradiometer (MODIS), which is highly influenced by irrigation status and amount of irrigated water. However, because AVHRR was not designed for land applications, it is not well suitable for vegetation index monitoring. Specifically, the lack of accurate calibration, geometric registration and poor treatment of cloud noise result in high limit of accuracy. While mutlu et al. proved that due to its high temporal resolution and its support on global studies, MODIS data is valuable by providing information on the timing of key surface processes, such as irrigation (Mutlu et al., 2003).

Meanwhile, there have been developed several indexes added to temperature such as crop water shortage index (CWSI), vegetation supply water index (VSWI) and so on to monitor soil moisture with remote sensing data. The combination of temperature and growing condition of vegetation can indicate humidity of soil more exactly (Boegh et al., 1999).

We attempt in this study to map the irrigation area with parameters derived from MODIS data. Time series of NDVI and VSWI were used respectively to determine the extent of winter wheat and irrigated land.

\section{STUDY AREA AND MATERIALS}

North China Plain, the second largest alluvial plain in China, locates in lower reaches of Yellow River. The whole plain belongs to the warm-temperate climatic zone. The annual average temperatures vary between $8^{\circ} \mathrm{C}$ and $15^{\circ} \mathrm{C}$. The annual precipitation ranges from $600 \mathrm{~mm}$ to $800 \mathrm{~mm}$, however, water resources are unevenly distributed spatially and temporally. The plain covers an area of about 53950000 square kilometers, most of which is less than $50 \mathrm{~m}$ above sea level. Winter wheat, maize, cotton, soybean, tobacco and peanut are major crops. The crop farming system is three harvests within two years or two harvests yearly. The growing period is from March to November in most part of the plain. In the study, Beijing, Tianjin, Hebei, Henan and Shandong in the plain are under consideration, which are shown in Figure1.

Moderate Resolution Imaging Spectroradiometer (MODIS) is a key instrument on-board the Terra and Aqua satellites. It has 36 spectral bands, 7 spectral bands of which are used for land research. Compared with AVHRR data, MODIS data has higher spatial and spectral resolution. Terra passes from north to south across the equator in the morning, while Aqua passes south to north over the equator in the afternoon. Consequently, there are four times monitoring each location one day. MODIS data is suitable for regular observation of large region scale and global scale. Due to its narrower bands than AVHRR's, there is less influence on computing NDVI.

We used daily MODIS imagery from March to June in 2006, which is received by CAAS and vectors of province boundary downloaded from National fundamental geographic information system is assistant material to determine the extent of study area.

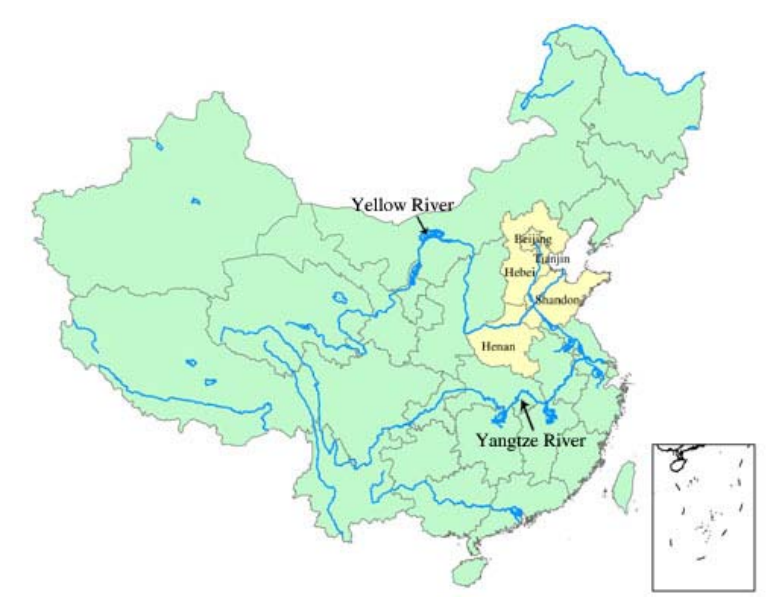

Figure 1 . The study area in North China Plain

\section{METHODS AND TECHNIQUES}

The frame method and procedures of the study can be described as Figure 2. After calibration, geometric registration and elimination bow-tie effect of daily MODIS data, we calculated daily NDVI, LST then VSWI. Then maximum value combination (MVC) of ten days was carried out in order to minimize cloud noise. Subsequently, the extent of winter wheat and irrigated land was obtained according to time series of NDVI and VSWI.

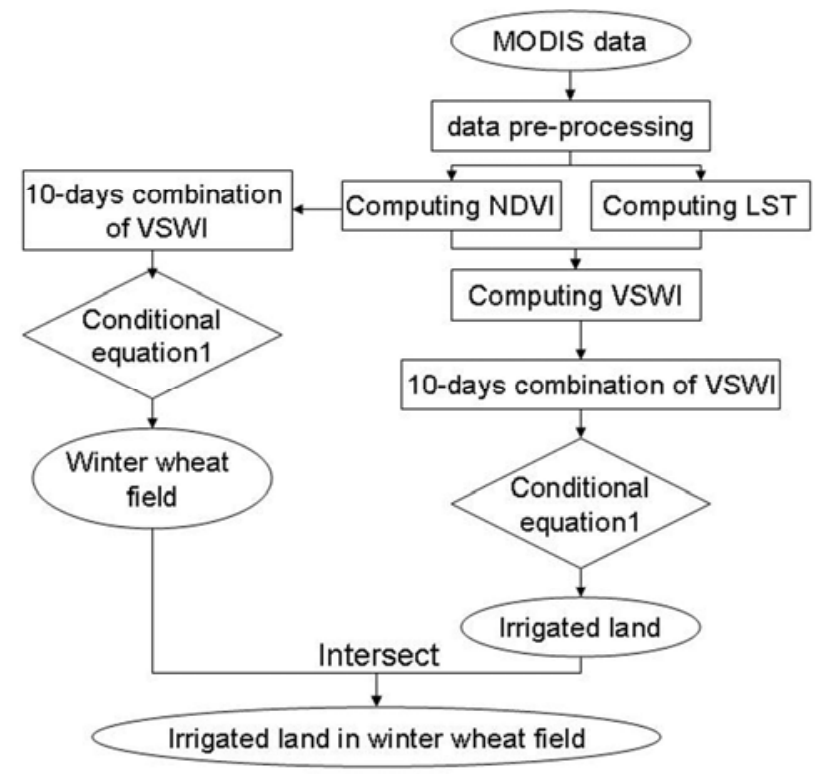

Figure 2. The frame method and routine of the study

\subsection{Computing NDVI and LST using MODIS data}

Normalized Difference of Vegetation Index (NDVI) is a simple numerical indicator that can be used to assess whether the area being observed contains live green vegetation or not and to analyze the green vegetation condition. It is calculated with the 
spectral reflectance measurements acquired in the red and near-infrared regions. Therefore, the reflectance measured from band 1 (visible: 0.620-0.670 microns) and band 2 (near infrared: 0.841-0.876 microns) of MODIS data are used to calculate the index:

$$
N D V I=\frac{\rho_{2}-\rho_{1}}{\rho_{2}+\rho_{1}}
$$

Because chlorophyll has higher reflectance in the near infrared than in the visible range, the larger NDVI is, the more live green vegetation is and the better green vegetation condition is.

Algorithms of retrieving land surface temperature (LST) from remote sensing data are various. After analyzing the current algorithms, we select the split-window algorithm proposed by Qin (Qin et al., 2005). Though MODIS data contain 8 thermal bands for earth observation, band 31 and 32 are especially suitable for LST retrieval required by agricultural drought monitoring (Qin et al., 2005). The general algorithm of split-window can be depicted as follows:

$$
T_{s}=A_{0}+A_{0} T_{31}-A_{0} T_{32}
$$

$T_{s}$ represents LST. $T_{31}$ and $T_{32}$ are brightness temperatures of band 31 and 32 of MODIS data, respectively. The unit of $T_{s}, T_{31}$ and $T_{32}$ is $\mathrm{K} . A_{0}, A_{1}$ and $A_{2}$ are split-window parameters, which are functions of the transmittance of atmosphere and the emissivity of ground. The brightness temperatures, the transmittance of atmosphere and the emissivity of ground can be computing with MODIS data.

\subsection{Determination of VSWI}

Vegetation supply water index (VSWI), a function of NDVI and LST, is an effective index reflecting soil moisture. When water supply is regular, vegetation index and canopy temperature of crop are stable. Whereas, if no irrigation were carried out during the growing periods of crop, canopy temperature would become high and crop would grow bad, subsequently VSWI would decrease. Therefore, it is consistently shown that single date imagery may be sufficient to identify soil moisture using VSWI, while multi-date VSWI is needed to reflect changing of soil moisture.

The computing of VSWI can be depicted as follows:

$$
V S W I=\frac{N D V I}{T_{s}}
$$

\subsection{Mapping the region of winter wheat}

There are bare land, water, town, forest and agricultural land in the plain. It is possible to distinguish green vegetation and non-green vegetation with NDVI. While the major work in this step is to separate forest from green vegetation to acquire the extent of agricultural land being studied.

Winter wheat is the major crop in North China Plain from March to the middle June. In the study, we suppose the extent of winter wheat as that of agricultural land. From regenerating at early March to tasselling at middle April, winter wheat grows well. In other words, NDVI increases all though this period, and the peak of NDVI happens at heading stage that is the middle of April. Subsequently, leaves and tassels become yellow, NDVI reduces due to decrease of greenness. At middle of June, the minimum of NDVI comes forth because of the harvest and senescence of winter wheat. Compared with winter wheat, NDVI of forest keeps raising from March to July.

Therefore, winter wheat and forest can be separate according to different regularity of NDVI changing. The result is shown in Figure 3.

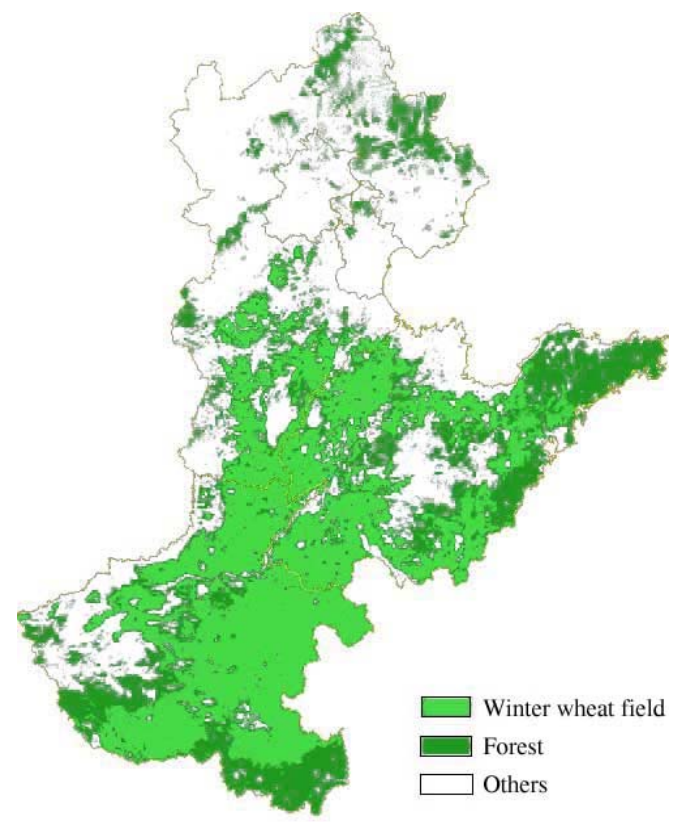

Figure 3. The extent of winter wheat and forest in North China Plain

\subsection{Mapping the irrigation area of winter wheat}

The water demand varies in different growing periods of crop. For winter wheat, there are four key periods to irrigate: tillering stage before winter, regenerating period, booting stage and heading stage. In study area, the biggest water demand period is the heading stage from middle April to last April. Irrigation in this period can present irrigation in winter wheat area.

In the study, the relation between NDVI and LST proposed by Tian (Tian et al., 2005) is used to determine the VSWI thresholds distinguishing water shortage and irrigation. The thresholds in different ranges of NDVI would be different then the thresholds are shown in Table 1. If VSWI of one pixel is higher than corresponding VSWI threshold, the pixel is supposed to be irrigation region. After computing all pixels, the irrigation region in the study area can be confirmed, which is shown in Figure 4.

\begin{tabular}{|l|l|l|l|l|l|}
\hline NDVI & $0.2 \sim 0.3$ & $0.3 \sim 0.4$ & $0.4 \sim 0.5$ & $0.5 \sim 0.6$ & $0.6 \sim 0.7$ \\
\hline VSWI & 0.854 & 1.541 & 2.576 & 4.316 & 7.851 \\
\hline
\end{tabular}

Table 1. The thresholds in different ranges of NDVI 


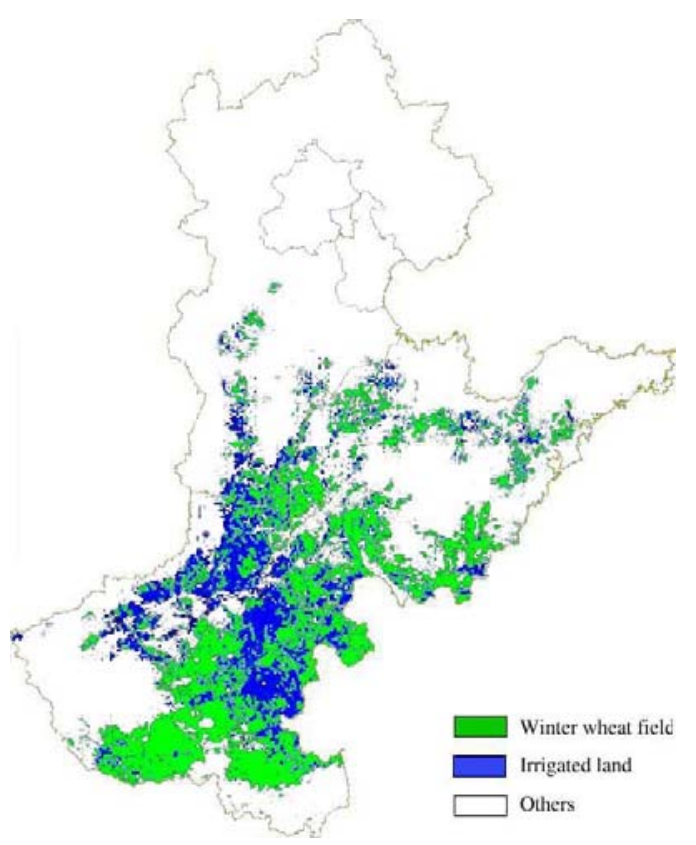

Figure 4. The irrigated land in winter wheat field

\section{RESULTS}

Our results indicate that the irrigation area of winter wheat in North China Plain is 5.9 million hectare in 2006, 3.74 million hectare in Henan province, 0.54 million hectare in Hebei province and 1.55 million hectare in Shandong province. This figure is smaller than that from statistical yearbook. Figure 3.5 shows obvious the spatial variation of irrigation area in the region. More intensive irrigation can be observed on the southern Hebei province, the east and central of Henan province. Irrigation percentage of winter wheat in these areas can reach up to $70 \%$.

\section{CONCLUSIONS}

The study indicates that high temporal-frequency remote sensing data that is MODIS data can improve monitoring of irrigation in a large region and help regional mapping applications. Furthermore, it is free-cost, convenient and facile to obtain MODIS data and deal with the data.

In the study not only NDVI but also LST deriving from MODIS data is used to determine the irrigation area, and the results indicate that the combination of both factors is effective to obtain the useful information about crop growing conditions and canopy temperatures, both of which are relative to soil moisture.

To improve the accuracy of irrigation area, we recommend that an detailed investigation of crop calendar of different locations should be carried out. And experiments to determine VSWI thresholds of locations with various climates, topography and crop calendars which may impact irrigation system and soil moisture are recommended in the future in order to achieve more accurate irrigation area.

\section{REFERENCES}

Abuzar, M., McAllister, A., and Morris, M., 2001, Classification of seasonal images for monitoring irrigated crops in a salinity-affected area of Australia, Int. J. Rem. Sen. 22, 717-726.

Boegh, E., Soegaard, H., Hanan, N., Kabat, P., and Lesch, L., A Remote Sensing study of the NDVI-Ts relationship and transpiration from sparse vegetation in the Sahel based on high-resolution satellite data, Remote Sensing of Environment, 1999, 69: 224-240.

Draeger, W., 1976, Monitoring irrigated land acreage using Landsat imagery: An application example, USGS Open-file Report No. 76-630, USGS, Sioux Falls, S.D. 23 pp.

Eckhardt, D. W., Verdin, J. P., and Lyford, G. R., 1990, Automated update of an irrigated lands GIS using SPOT HRV imagery, Photogramm. Eng. Rem. Sen. 56, 1515-1522.

John Weier and David Herring, Measuring Vegetation (NDVI \& EVI).http://earthobservatory.nasa.gov/Library/MeasuringVegetati on/measuring_vegetation_1.html (accessed 28 Apr. 2008 )

Moulin, S., Kergoat, L., Viovy, N., \& Dedieu, G. G. (1997). Global-scale assessment of vegetation phenology using NOAA/AVHRR satellite measurements. Journal of Climate, 10, 1154-1170.

Mutlu Ozdogan, Curtis E. Woodcock and Guido D. Salvucci. The value of MODIS data in support of local mapping of irrigated lands with Landsat Data. International Journal of Remote Sensing. 2003.2.

National fundamental geographic information system, http://nfgis.nsdi.gov.cn/asp/userinfo.asp (accessed 4 May 2007)

Qin Zhihao, Gao Maofang, Qin Xiaomin, Li Wenjuan, Xu bin. Methodology to retrieve land surface temperature from MODIS data for agricultural drought monitoring in China. Journal of Natural Disasters. 2005, Vol.14, No.4.

Rundquist, D. C., Hoffman, R. O., Carlson, M. P., and Cook, A. E., 1989, The Nebraska Center-Pivot Inventory: An example of operational satellite remote sensing on a long-term basis, Photogramm. Eng. Rem. Sen. 55, 587-590.

Tian Guoliang et al, 2006. Thermal Remote Sensing. Publishing House of Electronics Industry, Beijing.

White, M. A., Thornton, P. E., \& Running, S. W. (1997). A continental phenology model for monitoring vegetation responses to interannual climatic variability. Global Biogeochemical Cycles, 11, 217- 234.

ZHANG X., FRIEDL M., SCHAAF C.B., STRAHLER A.H., HODGES J.C.F., GAO F., REED B.C., and HUETE A., 2003, Monitoring vegetation phenology using MODIS. Remote Sensing of Environment, 84, 471-475. 